\title{
Biosensor measurement of purine release from cerebellar cultures and slices
}

\author{
Mark Wall • Robert Eason • Nicholas Dale
}

Received: 12 January 2010 /Accepted: 5 May 2010 / Published online: 25 May 2010

(C) The Author(s) 2010. This article is published with open access at Springerlink.com

\begin{abstract}
We have previously described an action-potential and $\mathrm{Ca}^{2+}$-dependent form of adenosine release in the molecular layer of cerebellar slices. The most likely source of the adenosine is the parallel fibres, the axons of granule cells. Using microelectrode biosensors, we have therefore investigated whether cultured granule cells (from postnatal day 7-8 rats) can release adenosine. Although no purine release could be detected in response to focal electrical stimulation, purine (adenosine, inosine or hypoxanthine) release occurred in response to an increase in extracellular $\mathrm{K}^{+}$concentration from 3 to $25 \mathrm{mM}$ coupled with addition of $1 \mathrm{mM}$ glutamate. The mechanism of purine release was transport from the cytoplasm via an ENT transporter. This process did not require action-potential firing but was $\mathrm{Ca}^{2+}$ dependent. The major purine released was not adenosine, but was either inosine or hypoxanthine. In order for inosine/hypoxanthine release to occur, cultures had to contain both granule cells and glial cells; neither cellular component was sufficient alone. Using the same stimulus in cerebellar slices (postnatal day 7-25), it was possible to release purines. The release however was not blocked by ENT blockers and there was a shift in the $\mathrm{Ca}^{2+}$ dependence during development. This data from cultures and slices further illustrates the complexities of purine release, which is dependent on cellular composition and developmental stage.
\end{abstract}

Keywords Inosine · ENT · Glia · Granule cell · Biosensor

M. Wall $(\bowtie) \cdot$ R. Eason $\cdot$ N. Dale

Neuroscience Group, Department of Biological Sciences,

University of Warwick,

Coventry CV4 7AL, UK

e-mail: Mark.Wall@Warwick.ac.uk

\section{Introduction}

The neuromodulator adenosine is involved in many physiological and pathological CNS processes [1-3]. Although the actions of adenosine are reasonably well characterised $[4,5]$ the mechanisms of extracellular adenosine production are complex [3, 6, 7]. A large number of studies, over many years have shown that adenosine can be released from brain tissue by a number of different stimuli (including hypoxia, ischemia, depolarisation, electrical stimulation, etc.) and by a variety of mechanisms (for review, see [7]). For example, an increase in extracellular adenosine release could occur following extracellular ATP metabolism (ATP can be released by exocytosis [7-9] or through gap junction hemi-channels [10]). Adenosine can also be transported from the cell cytoplasm by equilibrative transporters [7, 11, 12]. Recent data has described the release of adenosine [13] which has the properties of exocytosis $\left(\mathrm{Ca}^{2+}\right.$ and action-potential dependence $)$ but there is currently no direct evidence for either adenosine exocytosis or vesicular storage. Once released, adenosine is removed by conversion to inosine (by adenosine deaminase) and taken up into neurones and glia by transporters (equilibrative or concentrative).

We have previously shown that focal electrical stimulation within the molecular layer of cerebellar slices can release adenosine [13]. This process is both $\mathrm{Ca}^{2+}$ - and actionpotential-dependent, and several lines of evidence suggest that parallel fibre (granule cell axons) activity is required for adenosine release [13]. To show definitively that adenosine is released from parallel fibres in cerebellar slices is difficult, as parallel fibres could activate a downstream target which then releases adenosine. Thus, we have taken the approach of investigating whether isolated granule cells (in culture) can release adenosine with a similar mechanism to that 
observed in slices. We have used microelectrode biosensors, which respond in real-time to changes in purine concentration $[14,15]$. This is the first time that such biosensors have been used with primary cultured cells.

\section{Methods}

Preparation of granule cell cultures

The method for preparing granule cell cultures is based on [16].

\section{Solution composition (quantities for one preparation)}

Solution 1 (for $100 \mathrm{ml}$ ) $\mathrm{NaCl} 124 \mathrm{mM}, \mathrm{KCl} 5.4 \mathrm{mM}$, $\mathrm{NaH}_{2} \mathrm{PO}_{4} 1 \mathrm{mM}$, glucose $14.4 \mathrm{mM}$, phenol red $28 \mu \mathrm{M}$, HEPES $20 \mathrm{mM}, \mathrm{MgSO}_{4} 150 \mu \mathrm{M}$ and $0.3 \mathrm{~g}$ bovine serum albumin. The solution is filtered (sterile $0.2 \mu \mathrm{m}$ filter) and stored at $4^{\circ} \mathrm{C}$.

Solution 2 Ten millilitres of solution 1, DNaseI $0.1 \mathrm{mg} / \mathrm{ml}$, trypsin inhibitor from soy bean $0.52 \mathrm{mg} / \mathrm{ml}$ (Invitrogen) and $3.2 \mathrm{mM} \mathrm{MgSO}_{4}$.

Solution 3 Ten millilitres of solution $1,130 \mu \mathrm{M} \mathrm{CaCl}_{2}$ and $2.6 \mathrm{mM} \mathrm{MgSO}_{4}$.

Neurobasal medium Twenty millilitres of Neurobasal (Fisher), glutamine $1.5 \mathrm{mM}$, penicillin $10 \mathrm{U} / \mathrm{ml}$ streptomycin $10 \mu \mathrm{g} / \mathrm{ml}$ and $400 \mu \mathrm{l} \mathrm{B}-27$ (50×, Fisher).

The cerebellum was removed from a postnatal day 7 8 (P7-8) Wistar rat and transferred into Krebs solution $\left(\mathrm{NaCl} 124 \mathrm{mM}, \mathrm{KCl} 5.4 \mathrm{mM}, \mathrm{NaH}_{2} \mathrm{PO}_{4} 1 \mathrm{mM}\right.$, glucose $14.4 \mathrm{mM}$, phenol red $28 \mu \mathrm{M}$, HEPES $20 \mathrm{mM}, \mathrm{MgSO}_{4}$ $150 \mu \mathrm{M}$ and bovine serum albumin $3 \mathrm{mg} / \mathrm{ml}$ ). Meninges and blood vessels were removed and following trituration and centrifugation ( $302 \mathrm{G}, 3 \mathrm{~min}$ ), cells were incubated for $15 \mathrm{~min}$ at $37^{\circ} \mathrm{C}$ in Krebs solution containing trypsin $(0.025 \%)$. After centrifugation ( $302 \mathrm{G}, 3 \mathrm{~min}$ ), cells were resuspended in Krebs solution, containing trypsin inhibitor $(0.52 \mathrm{mg} / \mathrm{ml})$ and DNAse $(0.1 \mathrm{mg} / \mathrm{ml})$, and passed through a $40-\mu \mathrm{m}$ cell strainer. The suspension was spun at $484 \mathrm{G}$ for $5 \mathrm{~min}$ and cerebellar granule neurons were purified by a pre-plating step in Neurobasal medium $\left(1 \mathrm{~h}, 37^{\circ} \mathrm{C}\right)$. For the harvesting of glia, coverslips were placed on the bottom of the dish so that the glia could stick to them. The suspended neuronal cells were plated on poly-l-ornithine coated coverslips (6-12 coverslips) at an approximate density of 400,000 cells per coverslip. Neurons were cultured in Neurobasal medium, containing $25 \mathrm{mM} \mathrm{KCl}, 2 \%$ B27, $1.5 \mathrm{mM}$ glutamine, penicillin $10 \mathrm{U} / \mathrm{ml}$ streptomycin and $10 \mu \mathrm{g} / \mathrm{ml}$. For experiments in which the proliferation of glial was reduced, the mitotic inhibitor $(1 \mu \mathrm{M}$ $\beta$-D-arabinofuranoside hydrochloride) was added to the Neurobasal media $24 \mathrm{~h}$ after culture preparation. The mitotic inhibitor was then present in all media.

Immunohistochemistry

Following recording, coverslips were incubated in 4\% paraformaldehyde (in $0.1 \mathrm{M}$ phosphate buffered saline, PBS) for $45 \mathrm{~min}$ at room temperature. The coverslips were then blocked in 10\% horse serum 90\% immunosolution (0.1 M PBS, $0.1 \%$ BSA, $0.1 \%$ sodium azide, $0.4 \%$ triton $\mathrm{X}-100$ and $\mathrm{pH} 7.4$ ) for $1 \mathrm{~h}$ at room temperature. Coverslips were washed three times (5-min washes) in $0.1 \mathrm{M}$ PBS. The coverslips were incubated with primary antibody to MAP2 (Mouse, Sigma, M4403) and GFAP (Chick, Millipore, AB5541) at 1 in 500 for $2 \mathrm{~h}$ at room temperature. Coverslips were washed three times (5-min washes) in 0.1 M PBS. The coverslips were incubated with the secondary antibody (one in 500) for $1 \mathrm{~h}$ at room temperature. The secondary for GFAP was goat anti-chick 594 (Fisher) and for MAP2 was goat anti-mouse 488 (Fisher).

\section{Preparation of cerebellar slices}

Transverse slices of cerebellar vermis $(400 \mu \mathrm{m})$ were prepared from male Wistar rats, at postnatal days 7-25 (P7-25). As described previously [13] and in accordance with the U.K. Animals (Scientific Procedures) Act (1986), male rats were killed by cervical dislocation and decapitated. The cerebellum was rapidly removed and slices were cut on a Microm HM $650 \mathrm{~V}$ microslicer in cold $\left(2-4^{\circ} \mathrm{C}\right)$ high $\mathrm{Mg}^{2+}$, low $\mathrm{Ca}^{2+}$ aCSF, composed of (mM): $127 \mathrm{NaCl}, 1.9 \mathrm{KCl}, 8 \mathrm{MgCl}_{2}, 0.5$ $\mathrm{CaCl}_{2}, 1.2 \mathrm{KH}_{2} \mathrm{PO}_{4}, 26 \mathrm{NaHCO}_{3}, 10$ D-glucose (pH 7.4 when bubbled with $95 \% \mathrm{O}_{2}$ and $5 \% \mathrm{CO}_{2}, 300$ mOSM). Slices were stored in normal aCSF $\left(1.3 \mathrm{mM} \mathrm{MgCl}_{2}, 2.4 \mathrm{mM}\right.$ $\mathrm{CaCl}_{2}$ ) at room temperature for $1-6 \mathrm{~h}$ before recording.

Recording from granule cell cultures and cerebellar slices

An individual granule cell culture (on a coverslip) or a cerebellar slice was transferred to a recording chamber, submerged in aCSF and perfused at $6 \mathrm{ml} / \mathrm{min}\left(30-32^{\circ} \mathrm{C}\right)$. The coverslip/slice was placed upon a suspended grid. All solutions were vigorously bubbled $\left(95 \% \mathrm{O}_{2} / 5 \% \mathrm{CO}_{2}\right)$ and all tubing had low gas permeability (Tygon). Purine biosensors were positioned just above the surface of the culture/slice (bent so their longitudinal surface was parallel to the culture surface or parallel to the molecular layer of cerebellar slices). Cultures were electrically stimulated with a concentric bipolar electrode (FHC) placed on the coverslip amongst the cells. Cultures were washed with aCSF for 20 30 minutes (to remove culture medium) before recordings were made. 


\section{Biosensor characteristics}

Biosensors were obtained from Sarissa Biomedical Ltd (Coventry UK). Biosensors consisted of enzymes entrapped within a matrix that was deposited around a Pt or Pt/Ir (90/10) wire etched to $\sim 50 \mu \mathrm{M}[14,15]$. The biosensors had an exposed length of $\sim 500 \mu \mathrm{m}$ that was coated with enzymes and thus capable of detecting purines. Biosensors were screened, which greatly reduced the responses to electroactive interferents (such as 5-HT, noradrenaline, dopamine and ascorbate). Four types of purine biosensor were used in this study. Firstly, a screened null sensor, possessing the matrix but no enzymes, was used to control for the release of any non-specific electro-active interferents. Secondly, screened biosensors containing adenosine deaminase, nucleoside phosphorylase and xanthine oxidase and (responsive to adenosine, inosine and hypoxanthine, ADO biosensor). Thirdly, screened biosensors containing nucleoside phosphorylase and xanthine oxidase (responsive to inosine, hypoxanthine, INO biosensor). And finally, screened ATP biosensors which consisted of the entrapped enzymes glycerol kinase and glycerol-3-phosphate oxidase [15]. Glycerol $(2 \mathrm{mM})$ was included in the aCSF, as glycerol is a co-substrate required for ATP detection. A full description of the properties of the biosensors has already been published but they show a linear response to increasing concentration of analyte, are fast to respond and have a rise time less than $10 \mathrm{~s}[14,15]$. Biosensors were calibrated with known concentrations $(10 \mu \mathrm{M})$ of adenosine, inosine and ATP. Adenosine biosensors had approximately equal sensitivity to adenosine, inosine and hypoxanthine. For non-differential ADO biosensor recordings, the concentration of purines was assessed from the adenosine or inosine calibration and is equivalent to $\mu \mathrm{mol} / \mathrm{L}^{\prime}$ [17]. The screening of sensors was assessed by applying $10 \mu \mathrm{M}$ of 5 -HT. Calibration was performed before the culture/slice was present in the perfusion chamber and after the culture/slice had been removed. This allowed measurement of any reduction in sensitivity during the experiment. Biosensor signals were acquired at $1 \mathrm{kHz}$ with a Micro CED (Mark 2) interface using Spike (Vs 6.1) software.

\section{Drugs}

All drugs were made up as $10-100 \mathrm{mM}$ stock solutions, stored frozen and then thawed and diluted with aCSF on the day of use. Adenosine, inosine, NBTI, and dipyridamole were purchased from Sigma. Erythro-9-(2-hydroxy-3nonyl) adenosine (EHNA) was purchased from TocrisCookson. TTX was purchased from Ascent Scientific. ATP was purchased from Roche. The mitotic inhibitor $\beta$ D-arabinofuranoside hydrochloride was purchased from Sigma.
All values are mean \pm SEM. Statistical significance $(P<0.05)$ was assessed using the Student $t$ test.

\section{Results}

Stimulation of granule cell cultures causes purine release

We have identified an action-potential and $\mathrm{Ca}^{2+}$-dependent form of adenosine release in the cerebellum [13]. One of the most likely sources of the adenosine is parallel fibres (granule cell axons). Thus, we have investigated whether isolated granule cells (in culture) can release adenosine with a similar stimulus. Initially, granule cells were cultured with and without high $(25 \mathrm{mM}) \mathrm{K}^{+}$concentrations in the media. Granule cells without the high $\mathrm{K}^{+}$concentration died after a few days and thus all experiments were conducted with cells cultured in a high $\mathrm{K}^{+}$concentration (which lasted up to $\sim 4$ weeks).

Biosensors were placed upon the surface of individual granule cell cultures (on glass coverslips). Using cultures that were 2-3 weeks old, we were unable to detect purine release following electrical stimulation, even with prolonged high-frequency trains (no difference between ADO and null sensors, $n=10$ coverslips, data not shown). This is not surprising as the stimulating electrode delivers a focal electrical stimulus, which will only activate a small number of cells directly under the stimulating electrode. In the slice, granule cell axons are aligned in tracts (within the molecular layer) and thus a large number will be activated by a focal stimulus. Thus, a stimulus was used which will depolarise all the cells in the culture, i.e. bath application of excitants. Depolarisation of the cells with $10-50 \mathrm{mM} \mathrm{KCl}$ did not produce reliable purine release (the ADO biosensor response was the same as the null sensor, $n=10$ coverslips, data not shown). Application of $100 \mu \mathrm{M}-1 \mathrm{mM}$ glutamate also did not reliably release purines ( $n=12$ coverslips, in most coverslips (ten out of 12) there was no purine release, in two cultures a small amount of purine release was detected). However, the simultaneous application of $25 \mathrm{mM}$ $\mathrm{KCl}$ and $1 \mathrm{mM}$ glutamate, reliably (14 out of 16 coverslips) induced a large current $(270 \pm 53 \mathrm{pA}$, range $49-813 \mathrm{pA})$ on the ADO biosensor with little or no current on the null sensor (Fig. 1a). The stimulus $(25 \mathrm{mM} \mathrm{KCl}+1 \mathrm{mM}$ glutamate) had no direct effect on the ADO biosensor, as once the biosensor was moved up from the culture surface the stimulus no longer produced a current ( $n=3$, Fig. $1 \mathrm{~b})$. Thus, the current is produced by detection of released purines and is equivalent to $1.8 \pm 0.2 \mu \mathrm{M}^{\prime}$ of purines (see "Methods" section).

The current produced by purine release had a slow time to peak (100-150 s) and a slow decay (500-600 s, Fig. 1a). As calibration curves for the sensors had a much faster rise 
Fig. 1 Purine release from granule cell cultures. a Traces from an ADO and null sensor placed on the surface of a 2-week granule cell culture (sensors were bent so that the sensing area was parallel to the culture surface). Increasing the concentration of $\mathrm{K}^{+}$from 3 to $25 \mathrm{mM}$ with simultaneous application of $1 \mathrm{mM}$ glutamate produced a large current on the ADO biosensor but no response on the null sensor. Inset, trace from a superimposed with a calibration trace $(10 \mu \mathrm{M}$ adenosine, dotted line) illustrating the speed of the current rise due to purine release is not defined by biosensor kinetics. b Trace from the same culture as a but the ADO biosensor has been lifted from the culture surface. Application of $25 \mathrm{mM} \mathrm{KCl}$ and $1 \mathrm{mM}$ glutamate had no effect on the ADO biosensor baseline. c Superimposed traces from an adenosine biosensor $(A D O)$ and an ATP biosensor placed on the surface of a 2-week culture. Although a large concentration of adenosine was released (following increase in $\mathrm{K}^{+}$concentration from 3 to $25 \mathrm{mM}$ plus $1 \mathrm{mM}$ glutamate) no ATP could be detected. d Superimposed traces from an adenosine biosensor (ADO) and an ATP biosensor placed on the surface of a 2-week culture. Application of a high voltage stimulus $(15 \mathrm{~V})$ from a stimulating electrode placed equidistant between the ADO and ATP biosensors produced the release of ATP (by electroporation). However, there was very little breakdown of the released ATP to adenosine. e Superimposed traces from an adenosine biosensor (ADO) and an ATP biosensor placed on the surface of a 2 week culture. Application of exogenous ATP $(100 \mu \mathrm{M})$ produced a rapid rise on the ATP biosensor and a much smaller, slower rise on the ADO biosensor. Thus, the conversion of ATP to adenosine is relatively slow and is not complete

and decay ( $20 \mathrm{~s})$, the kinetics of the ADO biosensor current illustrates the kinetics of release from the cultures which is slow and prolonged (Fig. 1a, inset). Although most cultures $(88 \%)$ responded to a single stimulus, subsequent stimuli often produced a much smaller release of purines $(45 \pm 15 \%$ reduction, $n=12$ coverslips) suggesting a depletion of internal purine stores. However, this was not always the case, with some cultures releasing similar amounts of purines with two to four stimuli ( $n=4$ coverslips). With a reduced stimulus, $10 \mathrm{mM} \mathrm{KCl}+100 \mu \mathrm{M}$ glutamate or $100 \mu \mathrm{M}-1 \mathrm{mM}$ glutamate alone, it was sometimes possible to release smaller amounts of purines $\left(0.5 \pm 0.7 \mu \mathrm{M}^{\prime}, n=6\right.$ coverslips) which was sustainable for repeated stimuli (four to five, not illustrated). However, purine release (with this weaker stimulus) was not reliable, with many cultures (48\%) not responding (but still able to release purines with the stronger stimulus, $25 \mathrm{mM} \mathrm{KCl}+1 \mathrm{mM}$ glutamate).

No ATP release can be detected

By replacing the null sensor with an ATP biosensor, we investigated whether the purines detected arose from the breakdown of extracellular ATP. The strong stimulus could possibly result in cell death leading to ATP liberation from the cytoplasm. In all experiments, no ATP could be detected following stimulation $(n=15$ coverslips, detection limit $\sim 60 \mathrm{nM}$, Fig. 1c). Electroporation of cells (with a 15$25 \mathrm{~V}$ stimulus) released ATP $(0.9 \pm 0.2 \mu \mathrm{M})$ but only a very small amount of the released ATP was converted to adenosine ( $4 \%, n=3$, Fig. 1d). Addition of ATP

\section{a on culture surface}
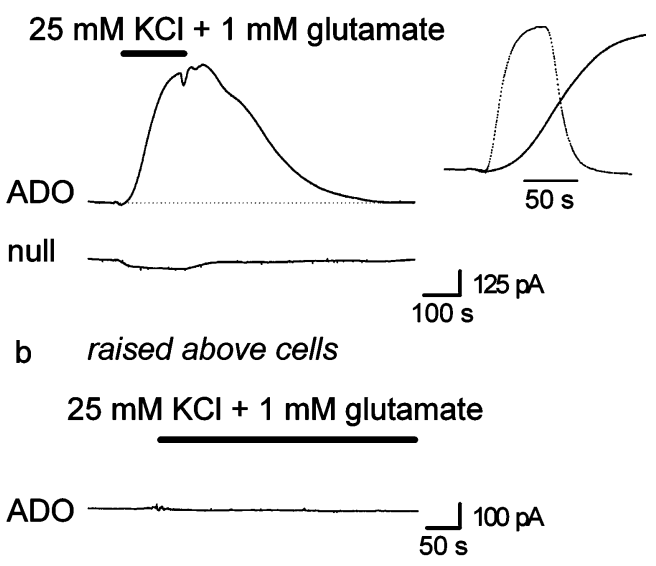

C $\quad 25 \mathrm{mM} \mathrm{KCl}+1 \mathrm{mM}$ glutamate

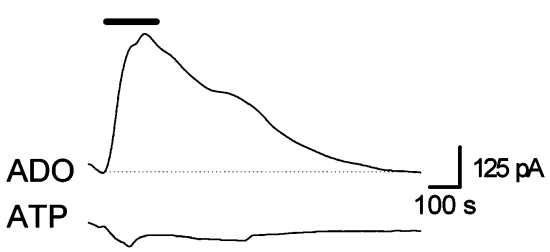

d

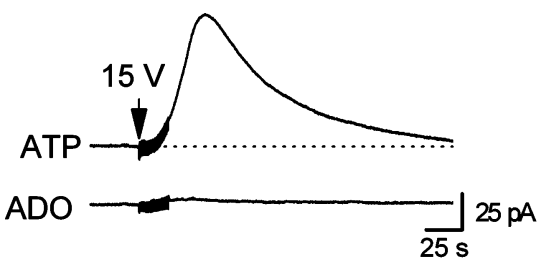

e

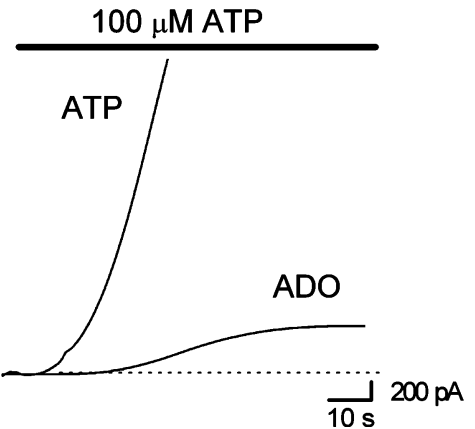

$(100 \mu \mathrm{M})$ to the cultures resulted in the slow formation of a small amount of adenosine (less than $2 \%, n=6$, Fig. 1e). Thus, although ectoATPases are present within the cultures, they do not appear to be efficient enough or in sufficient concentration to prevent ATP detection. Thus, we have no evidence that the released purines arise from the breakdown of extracellular ATP.

The purine released is not adenosine

We have used ADO biosensors (which detect adenosine, inosine and hypoxanthine) and INO biosensors (which 
detect only inosine and hypoxanthine) to determine which purines are released. Following a stimulus $(25 \mathrm{mM} \mathrm{KCl}+$ $1 \mathrm{mM}$ glutamate) the time to peak of currents on ADO and INO biosensors was very similar and so were the current amplitudes (once corrected for sensitivity, $n=5$, Fig. 2a). This suggests that the analyte detected is not adenosine but is either inosine or hypoxanthine as they can be detected by both biosensors. This contrasts with purine release in response to hypoxia in the hippocampus, where the signal on the ADO biosensor has a much faster time to peak than the signal on the INO signal demonstrating the release of adenosine [17]. Application of adenosine $(10 \mu \mathrm{M})$ to cultures produced only a small, slow rising current on the INO sensor (equivalent to $0.35 \pm 0.2 \mu \mathrm{M}$ inosine, i.e. only $3.5 \%$ of adenosine is broken down to inosine, $n=5$, Fig. 2b). Thus, it is unlikely that the inosine/hypoxanthine detected by the biosensors arises from the rapid extracellular breakdown of released adenosine. To confirm this, we have used EHNA. EHNA blocks the conversion of adenosine to inosine (by inhibiting adenosine deaminase), thus prevents the detection of adenosine and inhibits conversion of adenosine to inosine by adenosine deaminase within the cultures [12]. EHNA $(20 \mu \mathrm{M})$ had no significant effect on the currents measured by ADO biosensors (Fig. 2c, $n=5$ ). As a control, we checked that EHNA blocks the detection of adenosine by ADO biosensors [12] (Fig. 2d, $n=3$ ). Thus, the purine released is not adenosine but instead is either inosine or hypoxanthine.

The release of inosine/hypoxanthine is via equilibrative transport

We have investigated the mechanism of purines release. Unlike electrical stimulation in cerebellar slices [12], purine

Fig. 2 The purines released are adenosine metabolites. a, Superimposed traces from an $\mathrm{ADO}$ biosensor (dotted line) and INO biosensor placed on the surface of a 2-week culture. Addition of the stimulus ( $25 \mathrm{mM} \mathrm{KCl}$ and $1 \mathrm{mM}$ glutamate) caused an increase in current on both biosensors. The traces have been corrected for sensitivity to inosine and have similar rise-times and amplitudes. b Superimposed traces from an ADO and INO biosensor placed on the surface of a 2-week culture. Application of $10 \mu \mathrm{M}$ adenosine produced a large current on the ADO biosensor and a much smaller and slower rising current on the INO biosensor. The arrow illustrates that the ADO current is large when a current on the INO trace is first observed. c Superimposed traces from an ADO biosensor in control (solid line) and in $20 \mu \mathrm{M}$ EHNA (dotted line). The same ADO biosensor was placed on two different cultures. The stimulus $(25 \mathrm{mM}$ $\mathrm{KCl}$ and $1 \mathrm{mM}$ glutamate) was applied in control conditions on one culture and after incubation (10-15 min) with $20 \mu \mathrm{M}$ EHNA on the other culture. EHNA had little effect on the ADO biosensor current and thus the current must arise from the direct release of adenosine metabolites (inosine and or hypoxanthine). d Trace from an ADO biosensor. The current produced by adenosine $(10 \mu \mathrm{M})$ was blocked by co-application of EHNA $(20 \mu \mathrm{M})$ and recovered in wash. The dotted line is the baseline before adenosine application release was not blocked by TTX ( $1 \mu \mathrm{M}$ Fig. $3 \mathrm{a}, n=3)$ and thus does not require the firing of action potentials. In six experiments, removal of extracellular $\mathrm{Ca}^{2+}$ (substitution with equivalent concentration of $\mathrm{Mg}^{2+}$ ) prevented purine release (Fig. 3b). However, in some experiments $(n=3)$, release was still observed when $\mathrm{Ca}^{2+}$ was removed. By using an ATP biosensor we discovered that when purine release occurred in $\mathrm{Ca}^{2+}$ free aCSF, it was accompanied by a rapid release of large amounts of ATP $(\sim 3 \mu \mathrm{M}$ Fig. $3 c, n=3)$. In those cultures where no current was produced on the ADO biosensor there was also no ATP detected ( $n=2$ coverslips) and thus the adenosine detected probably arises from ATP metabolism. The mechanism of ATP release is unclear but could be via hemi-channels [10] or could represent cell death and subsequent release of cytoplasmic contents.

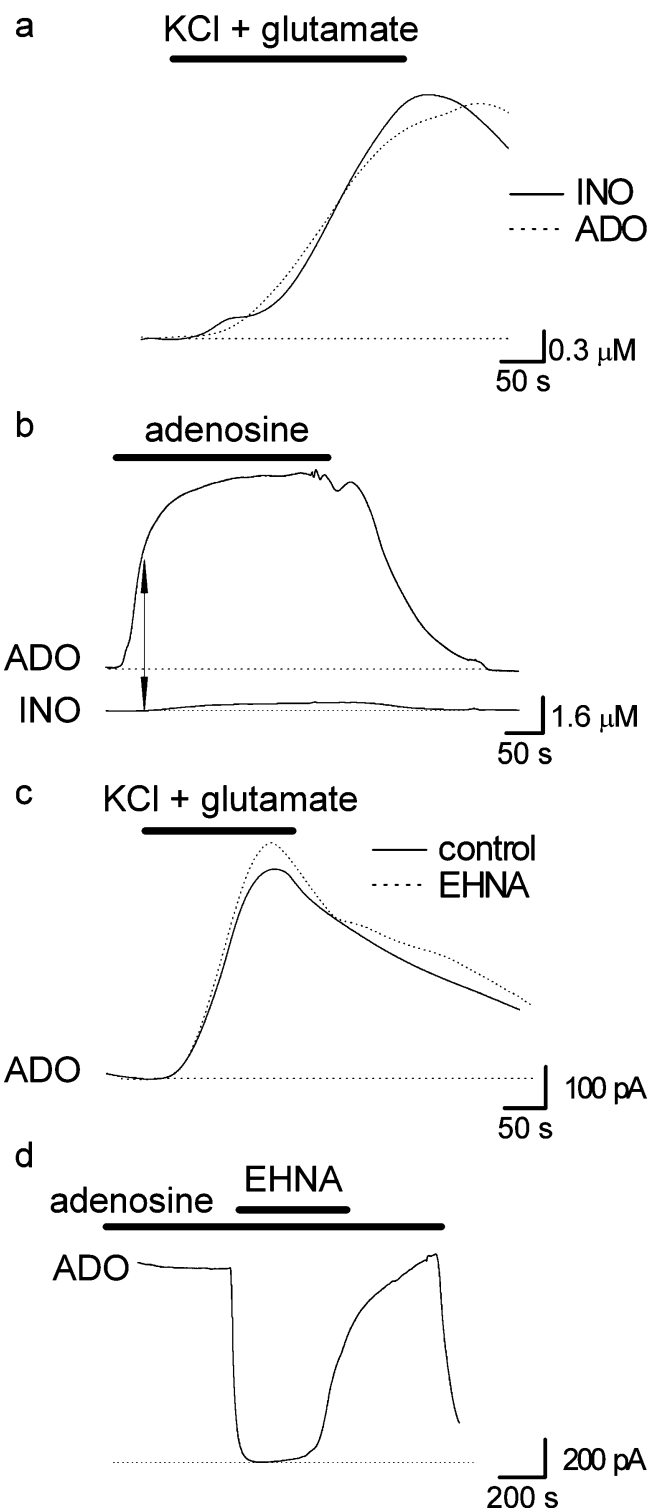


Fig. 3 The mechanism of purine release. a Trace from an ADO biosensor placed on the surface of a 2-3-week-old culture. Preincubation in $1 \mu \mathrm{M}$ TTX does not prevent purine release following application of $25 \mathrm{mM} \mathrm{KCl}$ and $1 \mathrm{mM}$ glutamate. b Trace from an ADO biosensor placed on the surface of a 2-3-week culture. Application of $\mathrm{Ca}^{2+}$-free aCSF $\left(\mathrm{Mg}^{2+}\right.$ increased to compensate for $\mathrm{Ca}^{2+}$ removal) caused a fall in the baseline current. Addition of $25 \mathrm{mM} \mathrm{KCl}$ and $1 \mathrm{mM}$ glutamate did not cause the release of purines but instead caused another fall in baseline. However, washing the $\mathrm{Ca}^{2+}$ back in (whilst stimulus was still present) resulted in purine release. c Traces from ATP and ADO biosensors placed on the surface of a 2-3week culture in zero $\mathrm{Ca}^{2+}$ aCSF. Application of $25 \mathrm{mM} \mathrm{KCl}$ and $1 \mathrm{mM}$ glutamate caused the release of ATP and adenosine, inosine, or hypoxanthine. d Trace from an INO biosensor placed on the surface of a 2-3-week culture. Pre-incubation with NBTI $(5 \mu \mathrm{M})$ and dipyridamole $(10 \mu \mathrm{M})$ prevented purine release following application of $25 \mathrm{mM} \mathrm{KCl}$ and $1 \mathrm{mM}$ glutamate. Following wash off, NBTI/ dipyridamole $(15-20 \mathrm{~min})$ purine release occurred following the stimulus. e Graph plotting mean concentration of purine released in control and in NBTI/dipyridamole illustrating that NBTI/dipyridamole significantly reduced purine release. Graph summarises data from six experiments

Studies on cortical neuron and glia cultures have shown that inosine can be released by equilibrative transport [18]. To test if this mechanism occurs with granule cells cultures, we have investigated the effects of the ENT blockers NBTI $(5 \mu \mathrm{M})$ and dipyridamole $(10 \mu \mathrm{M})$ [19]. Following the application of these transport blockers (for 10-15 min) the release of purines was either greatly reduced or in some cultures abolished $\left(0.94 \pm 0.2\right.$ vs. $0.17 \pm 0.05 \mu \mathrm{M}^{\prime}$ Fig. $3 \mathrm{~d}$,e $n=6$ ). Following wash, release often recovered (Fig. 3d) although the amount of recovery was variable. NBTI and dipyridamole did not produce any current on the ADO biosensor themselves and thus there appears to be very little basal uptake of purines within the cultures.

A reliable method of inducing adenosine release in cerebellar slices is to inhibit adenosine kinase (with iodotubercidin) this results in the efflux of adenosine via equilibrative transporters [20]. However, application of iodotubercidin $(2-4 \mu \mathrm{M})$ had no effect on the baseline current of ADO biosensors ( $n=4$, data not shown) and thus basal adenosine kinase activity in the cultures must be low (as a control, release could be evoked by $\mathrm{KCl}$ and glutamate, following iodotubercidin application). Purines can also be released from cerebellar slices by hypoxia [21]. However, prolonged hypoxia (10-15 min, bubbling with $\mathrm{N}_{2} / \mathrm{CO}_{2}$ ) had no effect on the ADO biosensor baseline (data not shown) and thus does not induce purine release in cultures ( $n=4$ coverslips). Thus, the major mechanism of purine release from the cultures is via equilibrative transport.

Purine release depends on culture composition

During the preparation of cultures we took steps to remove glial cells (see "Methods" section and [16]) and thus assumed that the purine release occurs from granule cells.
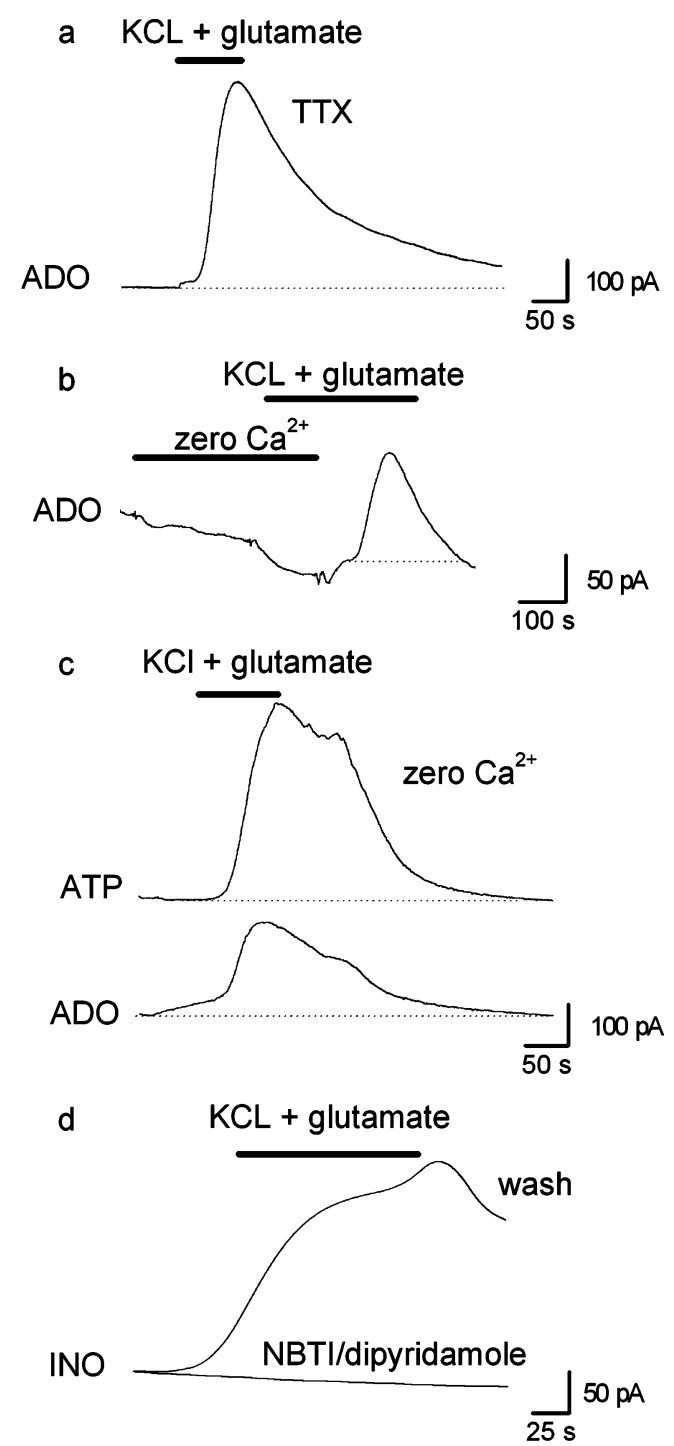

e

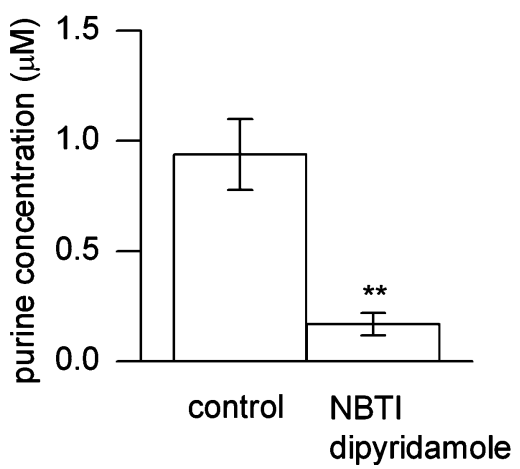

To confirm this and to investigate cell viability, we used immunohistochemistry. GFAP antibodies were used to identify glial cells and MAP-2 (neuronal dendritic protein) antibodies to identify granule cells. In cultures $2-3$ weeks old, cultures were mixed, with granule cells growing on a layer of glial cells ( $n=6$ coverslips, Fig. $4 a)$. During the 
Fig. 4 Culture composition determines purine release. Culture composition was determined by marking neuronal dendrites with MAP-2 antibodies (green) and marking glia with GFAP antibodies (red). Purine release was evoked by addition of $25 \mathrm{mM} \mathrm{KCl}$ and $1 \mathrm{mM}$ glutamate (black bar) and monitored with an ADO biosensor and null sensor placed on the culture surface. Example photographs and biosensor traces from: a 21-day culture, b 4-day culture, c 21-day culture with mitotic inhibitor present, d astrocyte only culture. Pictures were taken using an SP2 confocal microscope (single scan). Scale bar for photographs $(\mathbf{a}, \mathbf{b}$ and $\mathbf{c})$ is $30 \mu \mathrm{m}$ and $50 \mu \mathrm{m}(\mathbf{d})$. Note the different morphology of glia when cultured alone compared to morphology when cultured with neurones

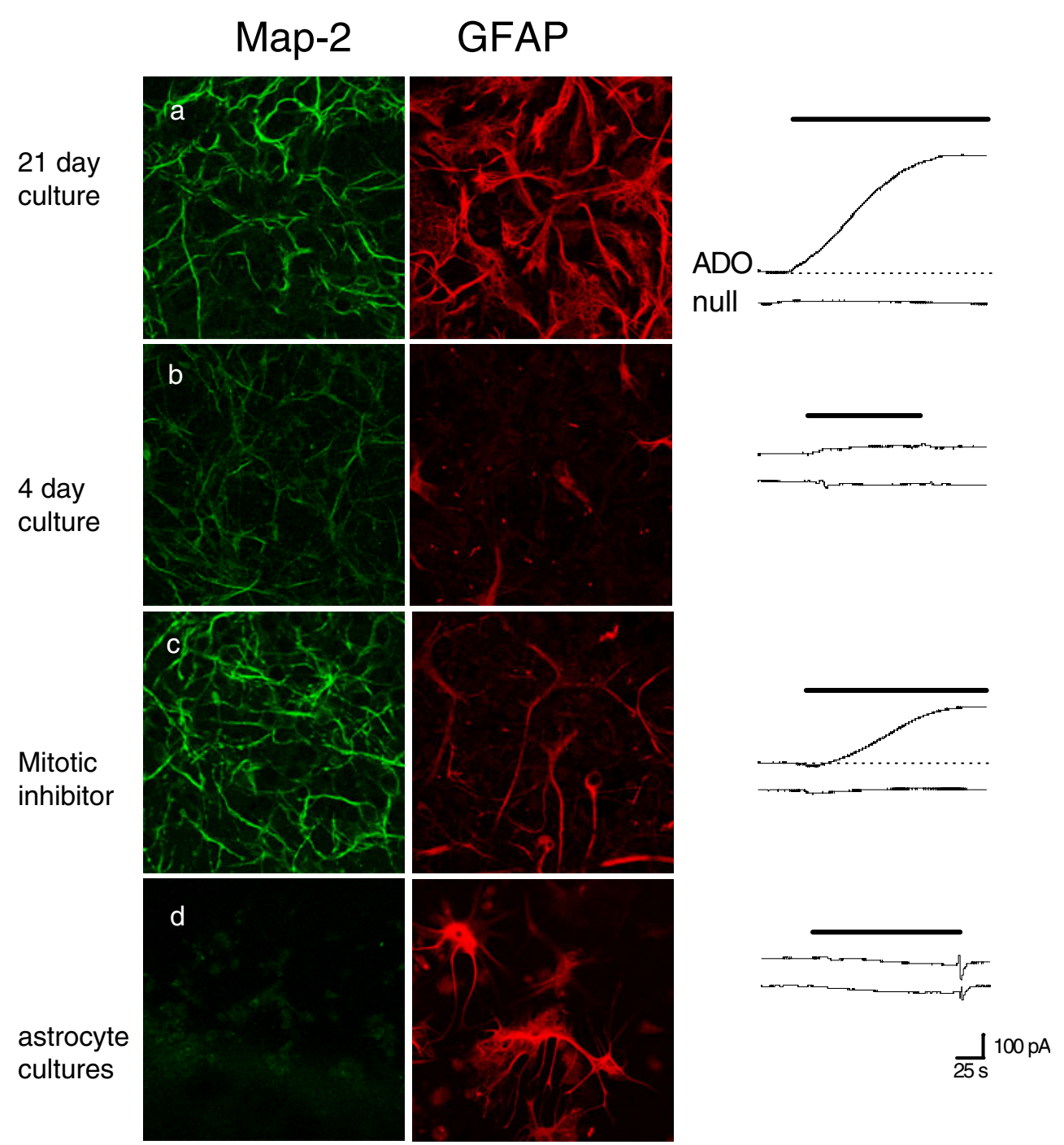

culture period, the small number of glia present during cell isolation must proliferate. Thus, the purine release measured could occur from either neurones or glia. There was no difference in the morphology or number of granule cells in stimulated (25 $\mathrm{mM} \mathrm{KCl}$ and $1 \mathrm{mM}$ glutamate) or unstimulated cultures, suggesting the stimulus does not produce wide spread cell death. To test the importance of glia in the release of purines we took two approaches: firstly, we assumed that 3-4-day-old cultures would contain very few glial cells, as there is little time for proliferation. This was confirmed by immunohistochemistry (Fig. 4b, $n=5)$. We were unable to record any purine release from these cultures $(25 \mathrm{mM} \mathrm{KCl}$ and $1 \mathrm{mM}$ glutamate, $n=10$ coverslips). In 7-day-old cultures, purine release occurred in $\sim 50 \%$ of cultures ( $n=6$ out of ten coverslips). In such cultures, the number of glia had increased (not illustrated). By 2 weeks, purine release was very reliable (see earlier). Although the reliability of purine release matches glial cell proliferation, it is also possible that neuronal differentiation occurs over this period and changes in the expression of proteins (such as ENTs) could account for the differences in purine release. Secondly, we grew cultures in the presence of the mitotic inhibitor $(1 \mu \mathrm{M} \quad \beta$-D-arabinofuranoside hydrochloride) which reduces glial cell proliferation. Immunostaining of 2-3-week-old cultures revealed a clear reduction in the number of glia in cultures treated with the mitotic inhibitor (Fig. 4c). There was also a significant $(P<$ $0.01)$ reduction in the amount of purines released from cells cultured in the presence of the mitotic inhibitor $(1.18 \pm$ $0.14 \mu \mathrm{M}^{\prime}$ vs $2.96 \pm 0.6 \mu \mathrm{M}^{\prime}$, six coverslips with a mitotic inhibiter and six control coverslips, interleaved experiments). This reduction in purine release could specifically reflect the loss of glia or could simply result from a reduction in total cell number if both neurones and glia release purines. In glia-only cultures (confirmed by immunohistochemistry, Fig. 4d), we could detect no purine release in response to $\mathrm{KCl}(25 \mathrm{mM})$ and glutamate $(1 \mathrm{mM}, n=10)$ but release was sometimes observed in response to the removal of extracellular $\mathrm{Ca}^{2+}$ (not illustrated). Interpretation of this data is difficult as changes in culture composition may affect 
differentiation and protein expression. However, it is clear that cultures are mixed (neurones and glia) and there is no obvious change in cell morphology (and presumably cell viability) following stimulation.

Purines release in acute cerebellar slices differs from release in cultures

To investigate whether a similar mechanism of purine release occurs in cerebellar slices, we have applied the same stimulus (25 $\mathrm{mM} \mathrm{K}^{+}$and $1 \mathrm{mM}$ glutamate) to cerebellar slices and measured purine release with biosensors. Although it is not possible to directly compare the age of animals used for slices with the days in culture, we have used slices from two ages of rats (P7-9 and P21-25) to investigate possible changes in purine release during cerebellar development.

In cerebellar slices from $\mathrm{P} 7-9$ rats addition of $\mathrm{KCl}$ $(25 \mathrm{mM})$ and glutamate $(1 \mathrm{mM})$ produced a large current on the ADO biosensor ( $449 \pm 66$ pA, Fig. 5a), with no current on the null sensor $(n=6)$. This current was equivalent to the release of $2.5 \pm 0.2 \mu \mathrm{M}^{\prime}$ adenosine/inosine. We found that the properties of release were similar to those found for release in cultures (Fig. 5b): not blocked by TTX (1 $\mu \mathrm{M}$, $n=3), \mathrm{Ca}^{2+}$ dependent $(n=4)$ and not accompanied by ATP release $(n=6)$. Blocking conversion of adenosine to inosine with EHNA $(20 \mu \mathrm{M}, n=3)$ had only a small effect on the current $(\sim 25 \%$ reduction) suggesting that the majority of the purine released was not adenosine. However, unlike cultures, purine release from cerebellar slices was not reduced by prolonged incubation (20-30 min) with NBTI $(5 \mu \mathrm{M})$ and dipyridamole $(10 \mu \mathrm{M}, n=4)$. Thus, the purine release in slices did not appear to occur via a transporter which is sensitive to NBTI/dipyridamole.

In cerebellar slices from $\mathrm{P} 21-25$ rats addition of $\mathrm{KCl}$ (25 $\mathrm{mM})$ and glutamate $(1 \mathrm{mM})$ also produced a large current on the ADO biosensor $(299 \pm 65 \mathrm{pA}$, equivalent to $1.46 \pm 0.5 \mu \mathrm{M}^{\prime}$ adenosine/inosine, $n=6$ ). Purine release was similar to release in slices from younger rats (Fig. 5b) in that it was insensitive to TTX ( $1 \mu \mathrm{M}, n=3)$, relatively insensitive to EHNA ( $20 \mu \mathrm{M}, \sim 15 \%$ reduction, $n=3)$ and insensitive to NBTI $(5 \mu \mathrm{M})$ /dipyridamole $(10 \mu \mathrm{M}, n=4)$. However, unlike purine release in slices from younger rats and in cultures, purine release was not inhibited by the removal of extracellular $\mathrm{Ca}^{2+}$ with no ATP detected on ATP biosensors $(n=4)$.

\section{Discussion}

We have used granule cell cultures to investigate whether the adenosine release observed in cerebellar slices [12] could be from granule cell axons. Although it was not possible to
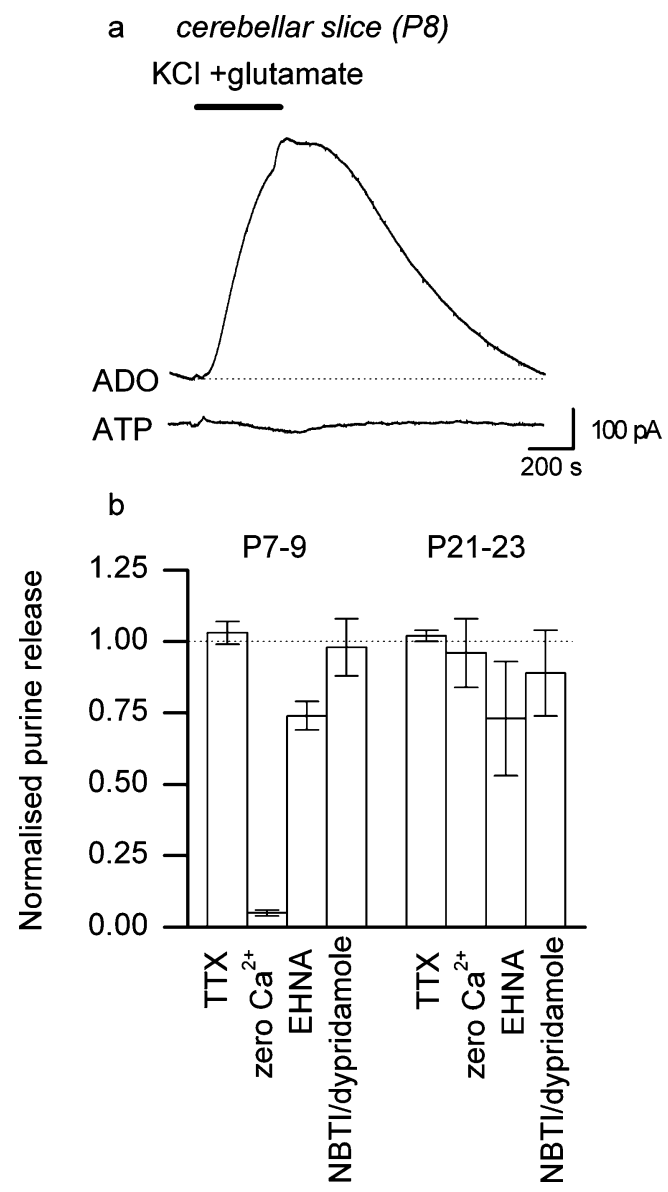

Fig. 5 The same stimulus produces purine release in acute cerebellar slices but release is not blocked by ENT inhibition. a Traces from $\mathrm{ADO}$ and ATP biosensors placed on the surface of the molecular layer of a cerebellar slice from a $\mathrm{P} 8$ rat. Addition of $25 \mathrm{mM} \mathrm{KCl}$ and $1 \mathrm{mM}$ glutamate produced a large current on the ADO biosensor but no signal on the ATP biosensor. b Graph summarising the effects of manipulations (addition of $1 \mu \mathrm{M}$ TTX, removal of extracellular $\mathrm{Ca}^{2+}$, addition of $20 \mu \mathrm{M}$ EHNA, addition of $5 \mu \mathrm{M}$ NBTI and $10 \mu \mathrm{M}$ dipyridamole) on purine release from slices from P7-9 rats and from P21-23 rats ( $n=3-6$ for each manipulation). The normalised purine release was calculated by dividing each manipulated (i.e. with zero $\mathrm{Ca}^{2+}$ or with a drug present) purine release current by the average current in control conditions. Data was corrected for differences in biosensor sensitivity across experiments

detect the action-potential dependent release of adenosine from granule cell cultures, it was possible to detect the release of adenosine metabolites (inosine/hypoxanthine) in response to a depolarising (stressful) stimulus. Although similar data has been described in other brain areas [7], this is the first time that purine release has been measured from primary cultured cells in real-time using microelectrode biosensors.

There are several possible reasons why the release of adenosine observed in slices was not observed in granule cell cultures. The simplest is that the adenosine release observed in slices is not from granule cells but instead is from a downstream target of parallel fibres and this target is 
absent from cultures. Such a target could be large cells such as Bergmann glia and Purkinje cells which are not present in the cultures. Alternatively, the cells in cultures are isolated from the cerebella of rats which are 7-8 days old. As it is not possible to record activity-dependent adenosine release in cerebellar slices from $\mathrm{P} 7-10$ rats [20], the mechanism of adenosine release may not be present in cultured cells if they do not develop further whilst in culture. Lastly, it could be that the cells (granule cells and glia) present in culture have different properties than those in acute cerebellar slices. The cells are cultured in $25 \mathrm{mM} \mathrm{K}^{+}$which greatly increases cell survival but may well change their properties, e.g. a greater resting $\left[\mathrm{Ca}^{2+}\right]_{\mathrm{i}}$ may induce widespread gene expression. This possibility is supported by the observation that NBTI/dipyridamolesensitive purine release that occurs in cultures is not observed in slices. Thus, either a different mechanism releases purines in cultured cells or a different transporter is involved. We have previously observed $[20,21]$ that in many slices, the efflux of adenosine produced by blocking adenosine kinase (with iodotubercidin) is not inhibited by blocking ENTs with NBTI/dipyridamole. Thus, the cells in slices either have a transporter which is insensitive to NBTI/dipyridamole or release purines by a transporterindependent mechanism. This difference between cultures and slices high lights the problem of extrapolating the mechanisms of purine release between different models.

\section{Mechanisms of purine release in culture}

Using a strongly depolarising and stressful stimulus ( $25 \mathrm{mM}$ $\mathrm{KCl}$ and $1 \mathrm{mM}$ glutamate), it was possible to reliably release inosine/hypoxanthine from granule cell cultures. Our data suggests that this stimulus results in the intracellular buildup of either inosine or hypoxanthine inside cells which is then transported from the cell via an NBTI/dipyridamolesensitive equilibrative transporter (ENT). It is unlikely that the intracellular inosine/hypoxanthine arise from the breakdown of adenosine, as blocking adenosine deaminase with EHNA had no effect on release [22]. Thus presumably intracellular AMP is converted to IMP plus ammonia (by AMP deaminase) and then IMP is metabolised to inosine (by 5 'nucleotidases) [23]. The ammonia produced is potentially toxic; for example, there is evidence that it produces swelling of astrocytes following liver failure [24]. The conversion of AMP to IMP predominates in rat C6 glioma cells in ATP depleting conditions [25]. The involvement of AMP deaminase is supported by the observation that the release of inosine/hypoxanthine is $\mathrm{Ca}^{2+}$ dependent. The affinity of AMP deaminase for AMP is increased in the presence of $\mathrm{Ca}^{2+}$ in human red blood cells [26] and $\mathrm{Ca}^{2+}$ calmodulin activates erythrocyte AMP deaminase [27]. The AMP appears to be produced as a result of intracellular
ATP metabolism rather than the conversion of adenosine to AMP as blocking adenosine kinase did not result in adenosine release. Studies in cortical neuron/astrocyte cultures [18, 22] have shown that inosine is released in an ENT-dependent mechanism from neurones in response to metabolic stress (oxygen/glucose deprivation or sodium cyanide). The stimulus we have used ( $\mathrm{KCl}$ and glutamate) will produce an increase in ATP metabolism because of the activation of exchange pumps following prolonged depolarisation and resultant ion movements. The influx of $\mathrm{Ca}^{2+}$ into cells is required for release (maybe to activate AMP deaminase) and this presumably comes via the opening of HVA $\mathrm{Ca}^{2+}$ channels and possibly via glutamate receptor channels.

Why is inosine/hypoxanthine released rather than adenosine? It is possible that the breakdown products of ATP metabolism are expelled from cells and have no signalling role. This seems unlikely as it would result in the loss of purines from the cells. Inosine is suggested to have a signalling role, activating $A_{3}$ receptors [28]. There is also evidence that inosine/hypoxanthine may play a neurotrophic role [29]. For example, inosine can stimulate morphological and biochemical differentiation in primary cultures of chick sympathetic neurons [30]. Inosine can also enhance the effects of NGF on neurite extension in PC12 cells [31]. The synthetic hypoxanthine derivative AIT-082 enhances the outgrowth of neurites in primary neuronal cultures [32]. Administration of hypoxanthine significantly improved somatosensory evoked potential recovery following ischemic brain injury [33]. The purine metabolite urate is a predictor of decline during Parkinson's disease, possibly suggesting raised levels of neuroprotective purines [34].

Which cells in culture release purines? This is currently unclear. Reducing the number of glia in cultures reduces purine release and neurone only cultures do not release purines. However, purine release does not occur in gliaonly cultures. These results have to be interpreted with caution as the astrocytes cultured without neurones clearly had a different morphology from those cultured with neurones and there was also a difference in neurones grown with reduced glia, neuronal processes were much more blebbed and cell bodies were stained more widely (not illustrated). Thus, the change in growing conditions may well affect the purine release mechanism and thus it is not possible to currently conclude which cells actually release purines in response to stimulation. However, it appears that the interaction between neurones and glia results in one or other (or both) cell types becoming competent to release purines.

The mechanisms of purine release remain controversial and as yet are not fully resolved. This study shows that purine release is highly complex and great care must be used when extrapolating between different stimuli and model systems. 
Acknowledgements We would like to thank Stephanie Zur Nedden for assisting with the granule cell cultures, Dr Kevin Moffat for assisting with the confocal microscopy and Professor Bruno Frenguelli for comments on earlier drafts. This work was supported by the MRC.

Open Access This article is distributed under the terms of the Creative Commons Attribution Noncommercial License which permits any noncommercial use, distribution, and reproduction in any medium, provided the original author(s) and source are credited.

\section{References}

1. Boison D (2006) Adenosine kinase, epilepsy and stroke: mechanisms and therapies. Trends Pharmcol Sci 27:652-658

2. Jacobson KA, Gao Z (2006) Adenosine receptors as therapeutic targets. Nature Reviews 5:247-264

3. Dale N, Frenguelli B (2007) Release of adenosine and ATP during ischemia and epilepsy. Curr Neuropharmacol 7:160-179

4. Fredholm BB, Ijzerman AP, Jacobson KA, Klotz KN, Linden J (2001) International Union of Pharmacology. XXV. Nomenclature and classification of adenosine receptors. Pharmacol Rev 53:527-252

5. Fredholm BB (2003) Adenosine receptors as targets for drug development. Drug News Perspect 16:283-289

6. Wall MJ, Dale N (2008) Activity-dependent release of adenosine: a critical re-evaluation of mechanism. Curr Neuropharmacol 6:329-337

7. Latini S, Pedata F (2001) Adenosine in the central nervous system: release mechanisms and extracellular concentrations. J Neurochem 79:463-484

8. Burnstock G (2007) Physiology and pathophysiology of purinergic neurotransmission. Physiol Rev 87:659-797

9. Jo YH, Schlichter R (1999) Synaptic co-release of ATP and GABA in cultured spinal neurons. Nat Neurosci 2:241-245

10. Pearson RA, Dale N, Llaudet E, Mobbs P (2005) ATP released via gap junction hemichannels from the pigment epithelium regulates neural retinal progenitor proliferation. Neuron 46:731-44

11. Sweeney MI (1996) Adenosine release and uptake in cerebellar granule neurons both occur via an equilibrative nucleoside carrier that is modulated by $\mathrm{G}$ proteins. J Neurochem $67: 81-88$

12. Craig CG, White TD (1993) $N$-methyl-D-aspartate and non- $N$ methyl-D-aspartate-evoked adenosine release from rat cortical slices: distinct purinergic sources and mechanisms of release. $\mathrm{J}$ Neurochem 60:1073-1080

13. Wall MJ, Dale N (2007) Auto-inhibition of parallel fibre-Purkinje cell synapses by activity dependent adenosine release. J Physiol 581:553-566

14. Llaudet E, Botting N, Crayston J, Dale N (2003) A three enzyme microelectrode sensor for detecting purine release from central nervous system. Biosens Bioelectron 18:43-52

15. Llaudet E, Hatz S, Droniou M, Dale N (2005) Microelectrode biosensor for real-time measurement of ATP in biological tissue. Anal Chem 77:3267-3273

16. Tomasellia B, Zur Nedden S, Podhraski V, Baier-Bitterlich B (2008) MAPK is an essential effector for purine nucleosidemediated neuroprotection of hypoxic PC12 cells and primary cerebellar granule neurons. Mol Cell Neurosci 38:559-568

17. Frenguelli BG, Llaudet E, Dale N (2003) High-resolution realtime recording with microelectrode biosensors reveals novel aspects of adenosine release during hypoxia in rat hippocampal slices. J Neurochem 86:1506-15

18. Parkinson FE, Xiong W (2004) Stimulus- and cell-type-specific release of purines in cultured rat forebrain astrocytes and neurons. J Neurochem 88:1305-1312

19. Noji T, Karaswa A, Kusaka H (2004) Adenosine uptake inhibitors. Eur J Pharm 495:1-16

20. Wall MJ, Atterbury A, Dale N (2007) Control of basal extracellular adenosine concentration in rat cerebellum. J Physiol 582:137-152

21. Atterbury A, Wall MJ (2009) Adenosine signalling at immature parallel fibre-Purkinje cell synapses in rat cerebellum. J Physiol 587:4497-4509

22. Parkinson FE, Sinclair CJ, Othman T, Haughey NJ, Geiger JD (2002) Differences between rat primary cortical neurons and astrocytes in purine release evoked by ischemic conditions. Neuropharmacology 43:836-46

23. Schultz V, Lowenstein JM (1976) Purine nucleotide cycle: evidence for the occurrence of the cycle in brain. J Biol Chem 251:485-492

24. Norenberg MD, Rao KV, Jayakumar AR (2005) Mechanisms of ammonia-induced astrocyte swelling. Metab Brain Dis 20:303318

25. Sinclair CJ, LaRivière CG, Young JD, Cass CE, Baldwin SA, Parkinson FE (2000) Purine uptake and release in rat C6 glioma cells: nucleoside transport and purine metabolism under ATPdepleting conditions. J Neurochem 75:1528-38

26. Almaraz L, García-Sancho J (1989) Activation by calcium of AMP deaminase from the human red cell. FEBS Lett 244:417-20

27. Mahnke DK, Sabina RL (2005) Calcium activates erythrocyte AMP deaminase [isoform E (AMPD3)] through a protein-protein interaction between calmodulin and the $\mathrm{N}$-terminal domain of the AMPD3 polypeptide. Biochemistry 44:5551-9

28. Guinzberg R, Cortés D, Díaz-Cruz A, Riveros-Rosas H, Villalobos-Molina R, Piña E (2006) Inosine released after hypoxia activates hepatic glucose liberation through A3 adenosine receptors. Am J Physiol Endocrinol Metab 290:940-51

29. Hasko G, Sitkovsky MV, Szabo C (2004) Immunomodulatory and neuroprotective effects of inosine. Trends Pharmacol Sci 25:152157

30. Zurn AD, Do KQ (1988) Purine metabolite inosine is an adrenergic neurotrophic substance for cultured chicken sympathetic neurons. Proc Natl Acad Sci U S A 85:8301-5

31. Braumann T, Jastorff B, Richter-Landsberg C (1986) Fate of cyclic nucleotides in PC12 cell cultures: uptake, metabolism, and effects of metabolites on nerve growth factor-induced neurite outgrowth. J Neurochem 47:912-9

32. Rathbone MP, Middlemiss PJ, Crocker CE, Glasky MS, Juurlink BH, Ramirez JJ, Ciccarelli R, Di Iorio P, Caciagli F (1999) AIT082 as a potential neuroprotective and regenerative agent in stroke and central nervous system injury. Expert Opin Investig Drugs $8: 1255-62$

33. Mink R, Johnston J (2007) The effect of infusing hypoxanthine or xanthine on hypoxic-ischemic brain injury in rabbits. Brain Res 1147:256-64

34. Ascherio A, LeWitt PA, Xu K, Eberly S, Watts A, Matson WR, Marras C, Kieburtz K, Rudolph A, Bogdanov MB, Schwid SR, Tennis M, Tanner CM, Beal MF, Lang AE, Oakes D, Fahn S, Shoulson I, Schwarzschild MA (2009) Urate as a predictor of the rate of clinical decline in Parkinson disease. Arch Neurol $66: 1460-8$ 